\title{
Eddy-Driven Exchange between the Open Ocean and a Sub-Ice Shelf Cavity
}

\author{
Marius ÅRThun,* PAul R. Holland, AND KeITH W. Nicholls \\ British Antarctic Survey, Cambridge, United Kingdom \\ DANiEL L. Feltham \\ Department of Meteorology, University of Reading, Reading, United Kingdom
}

(Manuscript received 13 June 2013, in final form 23 August 2013)

\begin{abstract}
The exchange between the open ocean and sub-ice shelf cavities is important to both water mass transformations and ice shelf melting. Here, the authors use a high-resolution $(500 \mathrm{~m})$ numerical model to investigate to which degree eddies produced by frontal instability at the edge of a polynya are capable of transporting dense high-salinity shelf water (HSSW) underneath an ice shelf. The applied surface buoyancy flux and ice shelf geometry is based on Ronne Ice Shelf in the southern Weddell Sea, an area of intense wintertime sea ice production where a flow of HSSW into the cavity has been observed. Results show that eddies are able to enter the cavity at the southwestern corner of the polynya where an anticyclonic rim current intersects the ice shelf front. The size and time scale of simulated eddies are in agreement with observations close to the Ronne Ice Front. The properties and strength of the inflow are sensitive to the prescribed total ice production, flushing the ice shelf cavity at a rate of $0.2-0.4 \times 10^{6} \mathrm{~m}^{3} \mathrm{~s}^{-1}$ depending on polynya size and magnitude of surface buoyancy flux. Eddy-driven HSSW transport into the cavity is reduced by about $50 \%$ if the model grid resolution is decreased to $2-5 \mathrm{~km}$ and eddies are not properly resolved.
\end{abstract}

\section{Introduction}

Antarctic continental shelf seas are important areas of dense water formation, and consequently affect the oceanic thermohaline circulation and climate system (Jacobs 2004). The principal mechanism of dense water formation is salt release from sea ice growth, which accumulates on some continental shelves to form highsalinity shelf water (HSSW). A key HSSW formation region is the southern Weddell Sea, where the production rate is approximately $2.8 \mathrm{~Sv}\left(1 \mathrm{~Sv} \equiv 10^{6} \mathrm{~m}^{3} \mathrm{~s}^{-1}\right)$ (Nicholls et al. 2009). Once the source waters over the continental shelf have been converted to HSSW there are several mechanisms that enable it to sink into the deep ocean, ultimately producing different flavors of Antarctic Bottom Water (AABW), the densest water mass in the world's oceans. One route is via a cold plume

\footnotetext{
* Current affiliation: Geophysical Institute, University of Bergen, and Bjerknes Centre for Climate Research, Bergen, Norway.
}

Corresponding author address: Marius Årthun, Geophysical Institute, University of Bergen, Allègaten 70, 5007 Bergen, Norway. E-mail: marius.arthun@gfi.uib.no that flows across the Filchner sill after the HSSW first has passed beneath Filchner-Ronne Ice Shelf, being cooled and slightly freshened to form ice shelf water (ISW; Fig. 1; Foldvik et al. 2004; Wilchinsky and Feltham 2009). This mechanism is thought to account for about $50 \%$ of the total HSSW flux from the Weddell Sea continental shelf (Weppernig et al. 1996).

In this paper, we focus on processes that aid the flow of HSSW into the sub-ice shelf cavity. For a geostrophic flow the ice front could present a strong dynamic barrier, as it provides a step in water column thickness that could restrict barotropic flow beneath the ice shelf by conservation of potential vorticity. Early three-dimensional numerical models of ice shelf cavities (Determann and Gerdes 1994; Grosfeld et al. 1997) suggested this to be a major factor controlling the exchange between the open ocean and the cavity. However, this barrier would only be expected in the unstratified case. Observations along the Ronne Ice Front and within the cavity (Nicholls 1996; Foldvik et al. 2001; Nicholls et al. 2003) have later shown that flow into the cavity is highly seasonal, with a peak inflow during midwinter and a secondary inflow period during summer, despite the fact that HSSW is present all year round at the ice front. The summertime 


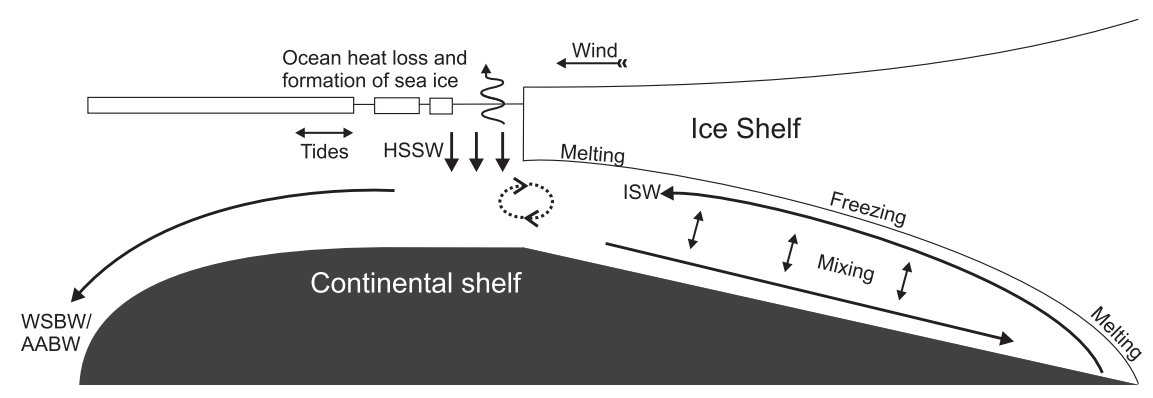

FIG. 1. 2D schematic of HSSW production and flow beneath an ice shelf. HSSW is produced as a result of intense sea ice formation in an ice-front polynya, an area of open water or thin ice created by offshelf winds and ocean currents. Upon entering the cavity HSSW interacts with the ice shelf base, producing cold and fresh ISW. The ISW escaping the cavity descends the continental slope and mixes with offshelf water masses to ultimately form Weddell Sea bottom water (WSBW), a precursor to AABW. See, for example, Nicholls et al. (2009) for details.

inflow is a result of restratification of the water column after the previous winter's convection, thus decoupling the water column, breaking the barotropic potential vorticity barrier, and enabling plumes to enter the ice shelf cavity more easily (Nicholls and Makinson 1998). The wintertime inflow, which is the focus of this paper, occurs as a delayed response to sea ice growth and dense convection at the ice front (Holland and Jenkins 2001; Jenkins et al. 2004). However, the details of the dynamics governing this inflow remain poorly known.

A region of open water or thin ice in front of the Ronne Ice Front (Fig. 2), termed a coastal polynya, is a persistent feature in the Weddell Sea ice pack and an area of anomalously intense heat/buoyancy loss (Renfrew et al. 2002; Tamura et al. 2008; Haid and Timmermann 2013). The polynya is maintained throughout the winter by tides and prevailing offshore winds (Foldvik et al. 2001). Details of the ocean response to a steady polynya-type negative buoyancy flux have been examined in several idealized modeling studies (e.g., Gawarkiewicz and Chapman 1995; Visbeck et al. 1996; Chapman 1998, 1999; Wilchinsky and Feltham 2008). The immediate response is a density increase of the surface water and subsequent vertical mixing by convective plumes. The resultant density gradient between the dense chimney and the lighter ambient fluid creates a front that supports a geostrophic rim current flowing around the edge of the polynya, cyclonic at the surface and anticyclonic at the bottom. The rim current is in thermal-wind balance and susceptible to baroclinic instability. Eventually, baroclinic eddies develop on a scale comparable to the local Rossby radius of deformation, breaking down the front and transporting dense water away from the polynya region. An equilibrium is thus reached in which the lateral buoyancy transport balances the buoyancy flux at the surface. Consistent with this theory, Nicholls et al. (2003) found that during winter all velocity records from two moorings at the western Ronne Ice Front showed enhanced energy at periods between 1 and 4 days and suggested this to be caused by baroclinic eddies generated by frontal instability between the coastal polynya and the surrounding region with less HSSW formation. Makinson and Schröder (2004) further showed that the increased currents in this time band were associated with coherent structures with a horizontal extent of $10-15 \mathrm{~km}$ and velocities between 10 and $20 \mathrm{~cm} \mathrm{~s}^{-1}$.

The ability of a model to resolve eddies is a function of the number of grid cells per internal Rossby radius of deformation, which is $\sim 4 \mathrm{~km}$ in the Ronne depression (Nicholls and Makinson 1998). To amply resolve the Rossby radius the necessary grid size is thus $<1 \mathrm{~km}$, a resolution not achieved by previous regional modeling studies of sub-ice shelf flow (Dinniman et al. 2011; Makinson et al. 2011; Galton-Fenzi et al. 2012; Timmermann et al. 2012). Coupled ice-ocean models also often lack the required spatial (and temporal) resolution of the atmospheric forcing data to properly simulate polynya events (Mathiot et al. 2012; Hollands et al. 2013). Here, we use a high-resolution (500 m) model and an idealized setup of a sub-ice shelf cavity and open ocean system to address the role of a persistent ice-front polynya and eddy-driven exchange across the ice front. The model setup is presented in section 2. Results are presented in section 3 and focus on the inflow of dense polynya water into the sub-ice shelf cavity, as well as its sensitivity to forcing parameters (section 4). A discussion with respect to observations and model setup is given in section 5 , and main conclusions are presented in section 6 .

\section{Model description}

To simulate convection in an Antarctic polynya and the ocean response within the sub-ice shelf cavity, we 


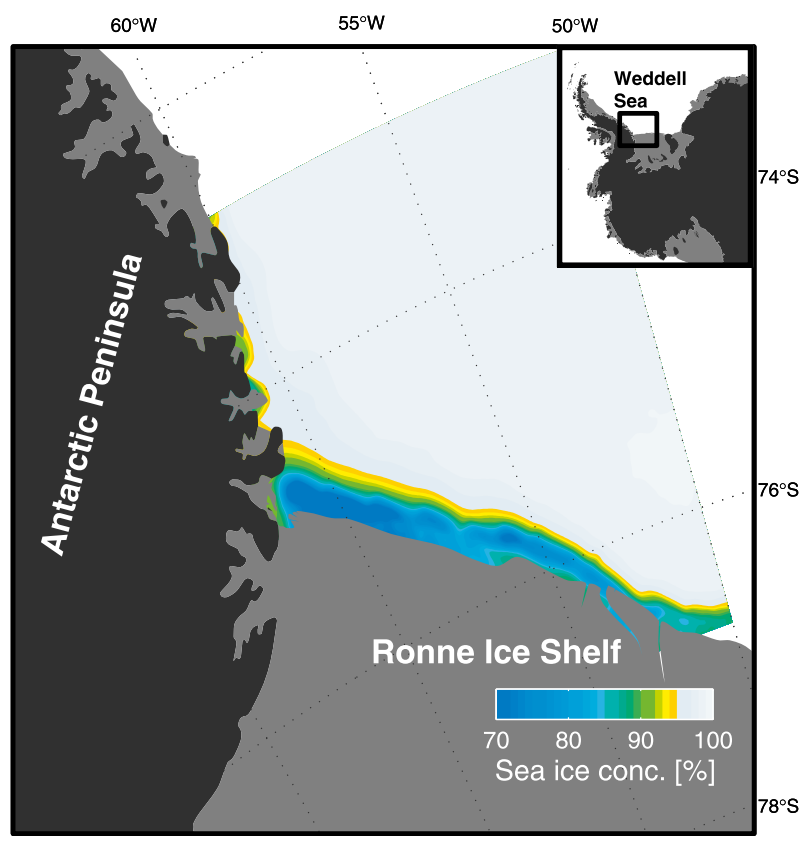

FIG. 2. Average sea ice concentration [Advanced Microwave Scanning Radiometer for Earth Observing System (AMSR-E), Spreen et al. (2008)] in the southwestern Weddell Sea for the period March-September 2003-07. The Ronne polynya is clearly visible as a band of low sea ice concentration along the ice front.

use the Massachusetts Institute of Technology General Circulation Model (MITgcm; Marshall et al. 1997a,b). The MITgcm is a $z$-coordinate, finite-volume model that solves the Navier-Stokes equations for a Boussinesq fluid on an Arakawa $\mathrm{C}$ grid. Advection of salt, momentum, and a tracer variable is computed via a third-order direct space-time flux-limited scheme. Because of the controlling influence of salinity upon density variations in the polar regions, we neglect variations in temperature for simplicity. Explicit diffusion of momentum and salt are equal with horizontal and vertical magnitudes of $15 \mathrm{~m}^{2} \mathrm{~s}^{-1}$ and $10^{-4} \mathrm{~m}^{2} \mathrm{~s}^{-1}$, respectively. The horizontal viscosity that we used was made as small as possible to minimize damping of the eddy field while ensuring numerical stability. The value is close to that used in studies with a similar model setup and grid spacing (e.g., Mahadevan 2006). A more realistic lower value would lead to even more important eddies, that is, it would strengthen our conclusions. The prescribed vertical diffusivity corresponds to the mean value observed in the northwestern Weddell Sea (Muench et al. 2002). In the case of static instability, a higher value of vertical diffusion $\left(10^{-2} \mathrm{~m}^{2} \mathrm{~s}^{-1}\right)$ is applied. These small values of the diffusivities ensure that the mixing is primarily controlled by convective overturning and instabilities. The tracer variable has no explicit diffusion. The ocean has a nonlinear free surface and a quadratic bottom drag with a drag coefficient of $2.5 \times 10^{-3}$. A fully nonlinear equation of state (McDougall et al. 2003) is used.

MITgcm does not need to make the hydrostatic approximation, and an important consideration in the present study is whether it is necessary to include nonhydrostatic dynamics. Nonhydrostatic terms become important as the ocean stratification and horizontal length scales of interest decrease (Marshall et al. 1997b). The representation of buoyant convection by hydrostatic and nonhydrostatic models and its sensitivity to grid resolution have been investigated by several authors (e.g., Dietrich and Lin 2002; Haine and Williams 2002; Mahadevan 2006). For a horizontal resolution between $100 \mathrm{~m}$ and $1 \mathrm{~km}$, they find that the vertical velocities are overestimated if hydrostatic balance is assumed and that individual plumes are too narrow. However, the differences are largely restricted to scales of less than $1 \mathrm{~km}$ (individual plumes), and minor differences are found in frontal development and the overall water mass conversion process. Based on these results and preliminary tests with our setup the model was run with the assumption of vertical hydrostatic equilibrium, as this decreases the computational expense by an order of magnitude. One nonhydrostatic run is also performed and the influence on the processes addressed herein is discussed in section 4 .

The model geometry is shown in Fig. 3a. The model domain is a high-latitude, uniformly rotating ( $f=$ $-1.14 \times 10^{-4} \mathrm{~s}^{-1}$, determined by $76^{\circ} \mathrm{S}$ ) box, covering an area of $480 \mathrm{~km} \times 360 \mathrm{~km}$. Mimicking the Ronne Ice Shelf and adjacent continental shelf, the seabed ranges from $400 \mathrm{~m}$ depth at the northern boundary to $650 \mathrm{~m}$ in the south. We use a resolution of $500 \mathrm{~m}$ in the horizontal and $10 \mathrm{~m}$ in the vertical. All boundaries are closed, with free-slip conditions applied and zero flux of salt and tracers.

To simulate a polynya, a salt flux is prescribed between $x=200$ and $300 \mathrm{~km}$ and between $y=180$ and $220 \mathrm{~km}$ (Fig. 3b) that varies across and along the polynya according to [after Haine and Marshall (1998)]:

$$
Q_{s}=\overline{Q_{s}}\left\{\tanh \left[2\left(p_{x, y}-L_{x, y} / 2\right) / L_{f}\right]+1\right\} .
$$

Here, $\overline{Q_{s}}$ is the salt flux midway from the polynya center, $p_{x, y}$ is the distance from the polynya center, $L_{x, y}$ is the polynya length/width, and $L_{f}=10 \mathrm{~km}$ is a characteristic length scale of the forcing. Using $\overline{Q_{s}}=2 \times 10^{-5} \mathrm{~m} \mathrm{~s}^{-1}$ yields values of $Q_{s}=\sim 4 \times 10^{-5} \mathrm{~m} \mathrm{~s}^{-1}$ at the center of the polynya. This approximates a sea ice production rate of $0.1 \mathrm{~m} \mathrm{day}^{-1}$, which is typical for Antarctic coastal polynyas (Renfrew et al. 2002; Tamura et al. 2008; Drucker et al. 2011). 

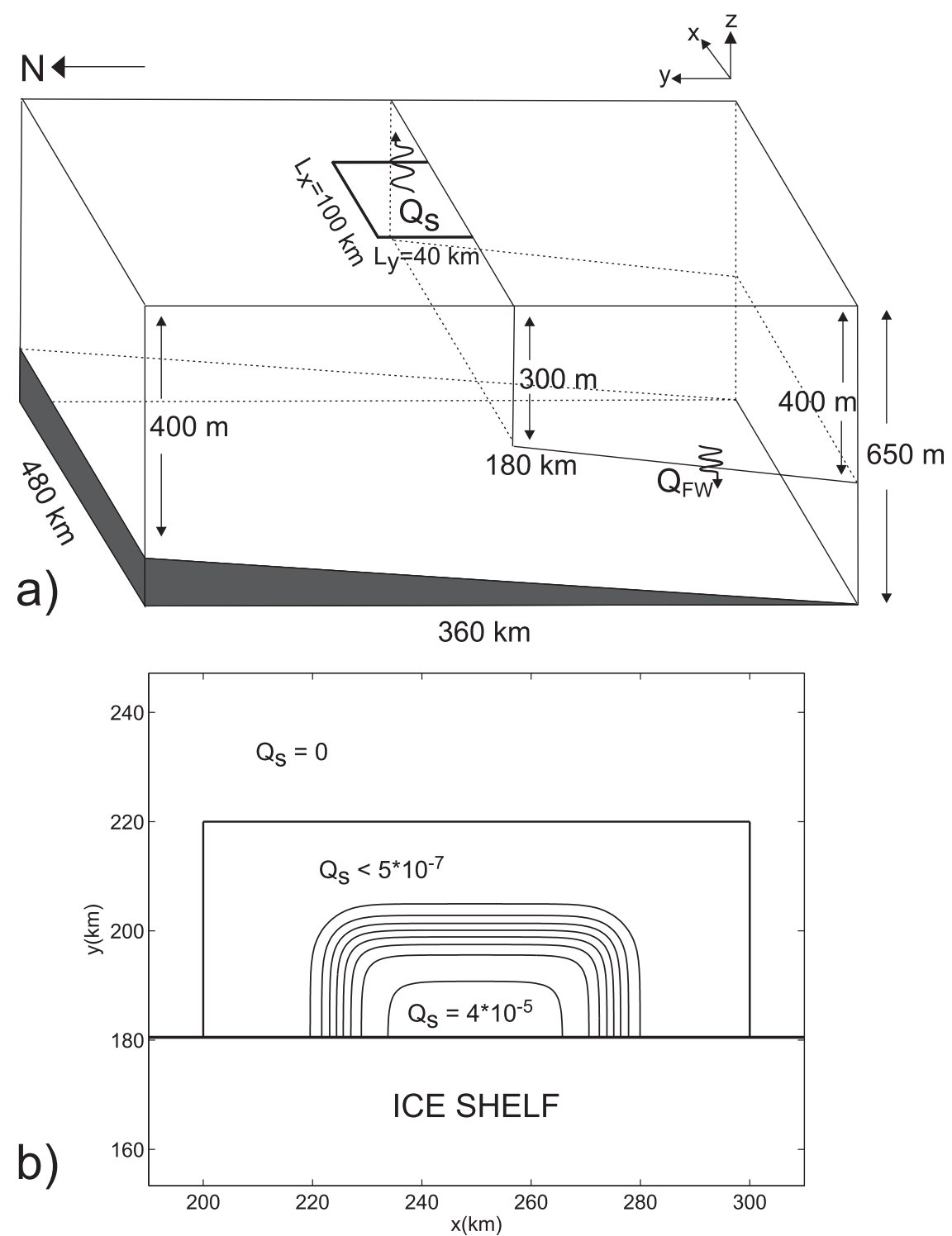

FIG. 3. (a) Model geometry and (b) surface salt flux $\left(\mathrm{m} \mathrm{s}^{-1}\right)$ for the control experiment (CTRL).

In nature, polynyas open and close on time scales of a few days as a response to atmospheric and oceanic forcing. However, Chapman (1999) showed that the ocean response to time-dependent polynya forcing is nearly the same as a fixed (from monthly to seasonal) time average. The applied buoyancy forcing corresponds to an inner region of newly formed and thin ice (large salt flux) and an outer region of thicker more consolidated ice, typical of coastal polynyas (Fig. 2; e.g., Fiedler et al. 2010). The choice of forcing function and associated parameters control the strength and scale of the horizontal density gradients, and thus the ocean response, produced by the polynya (Chapman and Gawarkiewicz 1997; Haine and Marshall 1998; Chapman
1999). The sensitivity to changes in forcing function is discussed in section 4 .

The floating ice shelf covers the southern $180 \mathrm{~km}$ of the model domain, is $300 \mathrm{~m}$ thick at the ice front, and thickens linearly southward to $400 \mathrm{~m}$ on the southern boundary. To isolate the effect of eddy-driven flow into the sub-ice shelf cavity, we disable the thermodynamic interaction between the base of the ice shelf and the underlying ocean water, and apply a free-slip condition. Basal melt, important to the stratification below the ice shelf, is, however, included by prescribing a freshwater flux $\left(Q_{\mathrm{FW}}=4.7 \times 10^{-5} \mathrm{~kg} \mathrm{~m}^{-2} \mathrm{~s}^{-1}\right)$ into the ocean. This corresponds to about $1.5 \mathrm{~m} \mathrm{yr}^{-1}$ of melt, representing an average of the melt rate observed over the outer Ronne 
TABLE 1. Metrics used to discuss the influence of forcing parameters and model setup (see section 4 for information about the model runs) to sub-ice shelf cavity inflow: mean bottom salinity anomaly underneath the polynya $S_{\text {bot }}^{\prime}$ for $t=20-60$ days; average depthintegrated HSSW $(S>34.5)$ inflow to the sub-ice shelf cavity at the ice front $\left[y=180 \mathrm{~km}, V_{\text {in }}\right.$, and $V_{\text {cav }}$ into the deep cavity $\left.(y=150 \mathrm{~km})\right]$. Relative changes with respect to CTRL $\Delta$ are also shown. Values presented for CTRL are mean plus or minus one std dev based on an ensemble of simulations with slightly perturbed initial conditions. HSSW transport for STRAT is calculated as the transport of water into the cavity that has a tracer concentration $>50 \%$.

\begin{tabular}{|c|c|c|c|c|c|c|}
\hline \multirow[b]{2}{*}{ Model run } & \multicolumn{2}{|c|}{$S_{\text {bot }}^{\prime}$} & \multicolumn{2}{|c|}{$V_{\text {in }}$} & \multicolumn{2}{|c|}{$V_{\text {cav }}$} \\
\hline & $\left(10^{-2} \mathrm{psu}\right)$ & $\Delta(\%)$ & (Sv) & $\Delta(\%)$ & $(\mathrm{Sv})$ & $\Delta(\%)$ \\
\hline CTRL & $4.9 \pm 0.1$ & - & $0.52 \pm 0.03$ & - & $0.19 \pm 0.01$ & - \\
\hline NARROW & 4.9 & 0 & 0.50 & -4 & 0.20 & +5 \\
\hline WIDE & 5.1 & +4 & 0.59 & +13 & 0.18 & -5 \\
\hline BIG & 7.9 & +61 & 1.03 & +98 & 0.37 & +95 \\
\hline WEAK & 2.6 & -47 & 0.36 & -31 & 0.12 & -37 \\
\hline STRAT & 0.0 & -100 & 0.37 & -29 & 0.08 & -58 \\
\hline TIDES & 4.9 & 0 & 0.56 & +8 & 0.14 & -26 \\
\hline NOMELT & 4.8 & -2 & 0.53 & +2 & 0.18 & -5 \\
\hline COARSE2 & 3.6 & -27 & 0.29 & -44 & 0.12 & -37 \\
\hline COARSE5 & 3.3 & -33 & 0.26 & -50 & 0.08 & -58 \\
\hline NONHYD & 4.7 & -4 & 0.57 & +10 & 0.23 & +21 \\
\hline
\end{tabular}

Ice Shelf (Jenkins and Doake 1991; Joughin and Padman 2003). The treatment of the pressure loading from the ice shelf is described in Losch (2008).

The model is run for 60 days using a time step of $48 \mathrm{~s}$. The length of the simulation is limited by the size of the domain, as the spreading of dense water encounters the boundary after this time, but is sufficient to allow the eddy field to fully develop. The simulation starts with an ocean at rest and with a uniform salinity of 34.5. To force convective cells to develop, the initial surface salinity field within the polynya is perturbed with random noise (zero mean) of small amplitude $(<0.005)$. The temperature is constant at $0^{\circ} \mathrm{C}$ throughout the simulation.

The above setup constitutes the CTRL. Additional experiments are also performed to assess how individual parameters influence the results (section 4). The inflow into the sub-ice shelf cavity will be characterized by the average bottom salinity beneath the polynya and the strength of the inflow. The latter is quantified in terms of the volume transport of salt-enriched polynya water $(S>34.5$, hereafter referred to as HSSW), calculated across the ice front $V_{\text {in }}$ (inflow only at $y=180 \mathrm{~km}$ ) and also within the deep cavity $V_{\text {cav }}$ (net transport at $y=$ $150 \mathrm{~km}$ ) to exclude water only briefly entering the cavity before returning to the ice front. In nature, transient inflows are important to basal melt as the inflowing water has a temperature above the local freezing point, but they do not contribute to the flushing of the cavity, which is the primary interest here. All data and plots are based on daily averages. Using averages over a shorter time period $(3 \mathrm{~h})$ revealed no significant changes to integrated properties of the flow of HSSW.

The results presented in section 3 are one realization of the eddy development given specific numerical methods and input parameters. Small perturbations in initial conditions can, for instance, potentially change the position and strength of eddies. To provide an estimate of uncertainty in our transport calculations we ran the model for the CTRL case an additional 10 times, each with a spatially different initial surface salinity perturbation. The amplitude range is kept constant. The standard deviations of HSSW transport based on these runs are presented as error margins (plus or minus one std dev) in Table 1.

\section{Eddy-driven exchange between the open ocean and sub-ice shelf cavity}

The temporal development of salinity around the polynya (Fig. 4) closely follows that described in Gawarkiewicz and Chapman (1995), as summarized above. In Fig. 4a the salinity anomalies are primarily confined to the forcing region, with frontal instabilities clearly visible on the boundary between the densest water in the central polynya and the less dense ambient water. The convective plumes are characterized by vertical velocities of up to $4 \mathrm{~cm} \mathrm{~s}^{-1}$. The salinity within the polynya increases for the first 13 days (Fig. 5) and then stays approximately constant for the rest of the simulation, implying that the surface buoyancy flux and export by eddies is in equilibrium after that time. After this, the salinity (Fig. 4) and velocity fields (Fig. 6) are dominated by eddies and eddy-driven exchange between the polynya and ambient waters.

The eddy development and flow around the polynya at depths below the ice shelf draft resemble that described in Wilchinsky and Feltham (2008) for the case of an offshore polynya. Eddies form within the baroclinic 

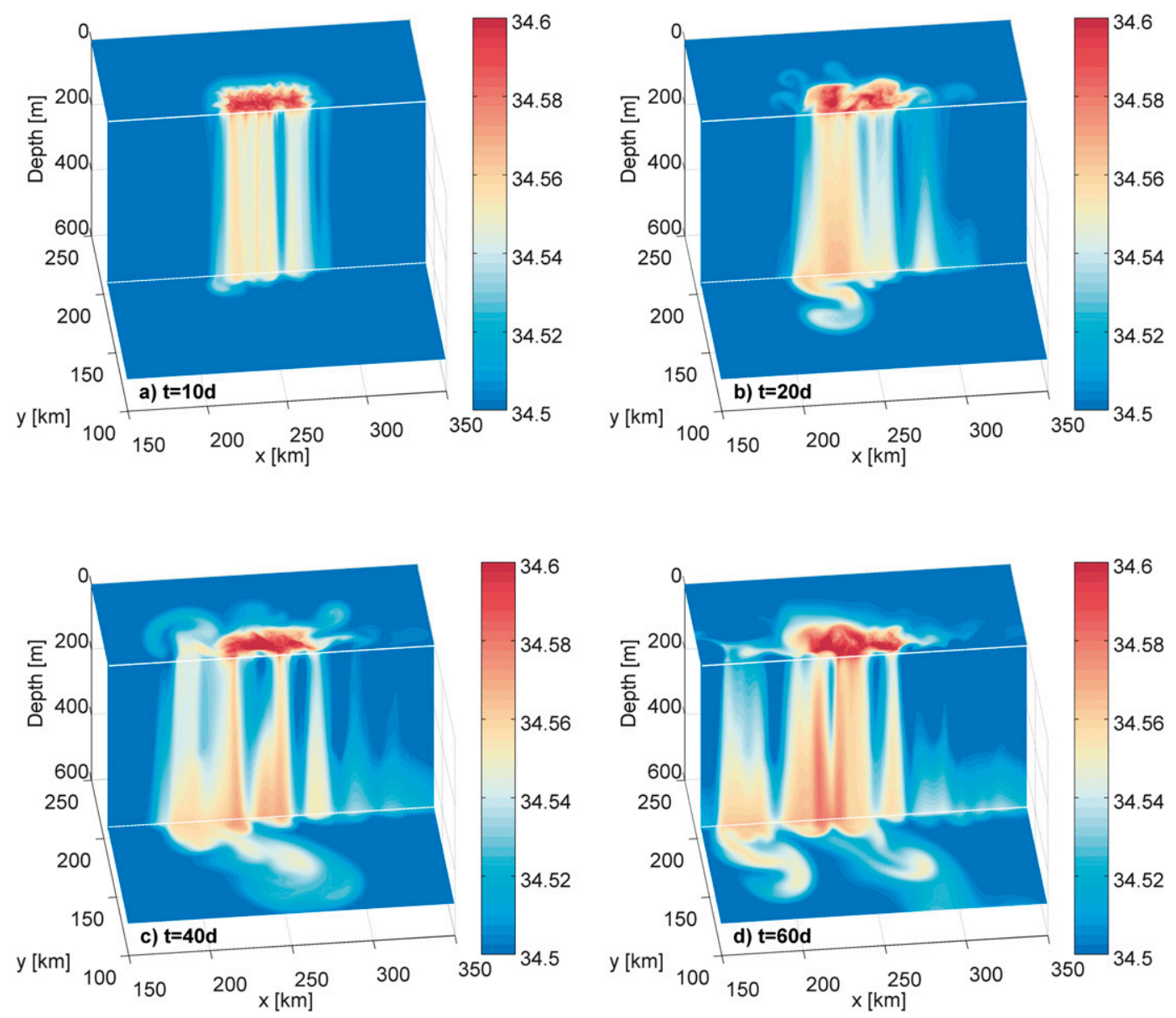

FIG. 4. Temporal evolution of salinity presented in a 3D cut-out view for (a) 10, (b) 20, (c) 40, and (d) 60 days. Separated by solid white lines in each panel is the surface salinity at the top, a vertical structure at the ice front in the middle, and a sub-ice shelf cavity salinity at 400-m depth at the bottom.

zone (forcing decay region) and are superimposed on an anticyclonic rim current (Fig. 6). In the presence of a coastline, this flow pattern yielded a westward coastal current (Wilchinsky and Feltham 2008). In the case of an offshore polynya or that of an ice shelf, the flow at the southwestern corner of the polynya is allowed to continue south, producing an anticyclonic flow in the outer part of the ice shelf cavity (Fig. 6). No coastal current is thus manifested and salinity anomalies only move about $50 \mathrm{~km}$ westward. The anticyclonic rim current is also what determines the mean flow into the cavity. The total flow field is still dominated by eddies; the domain-integrated eddy kinetic energy $\left[\mathrm{EKE}=1 / 2 \int_{V}\left(u^{\prime 2}+v^{\prime 2}\right) d V ; u^{\prime}\right.$ and $v^{\prime}$ being departures from the temporal average at each individual grid point] representing $68 \%$ of the total kinetic energy. We thus refer to the exchange between the open ocean and sub-ice shelf cavity as an eddy-driven flow.

The eddies at the ice front have a horizontal extent of about $10-15 \mathrm{~km}$. The eddy length scale should be related to the scale of instability (Rossby radius $R_{d}$ ) along the density front, determined by the salinity anomaly $\Delta S$ between the polynya and ambient water: $R_{d}=\sqrt{g^{\prime} h} / f=$ $\sqrt{g h \beta \Delta S} / f$, where $g^{\prime}$ is the reduced gravity, $h$ is the mixed layer depth, and $\beta$ is the haline contraction coefficient. A cross-frontal salinity difference of $0.05-0.1$ (Fig. 4) is associated with an $R_{d}=\sim 3-4.5 \mathrm{~km}$, and the modeled eddies are thus consistent with length scales of baroclinic instability of about $4 \times R_{d}$ (Pedlosky 1987). The ice-front eddies are further characterized by

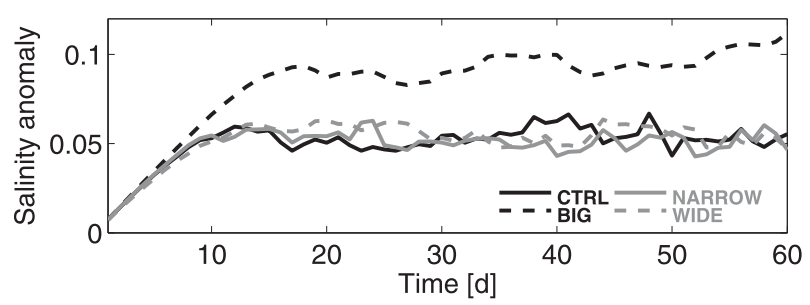

FIG. 5. Time series of depth-averaged salinity anomaly under the central polynya $(x=235-265 \mathrm{~km}, y=180-190 \mathrm{~km})$. 


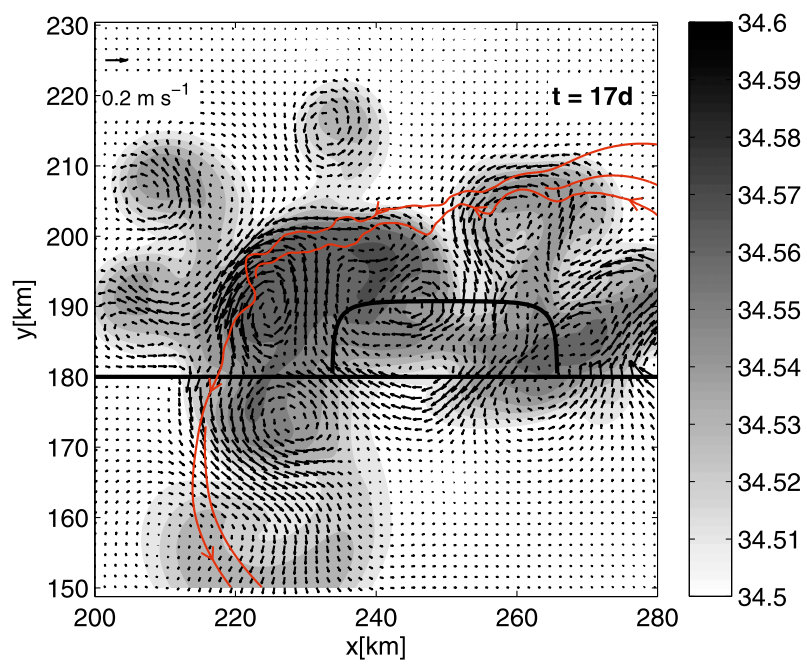

FIG. 6. Horizontal section of salinity (contours) and velocity vectors at $400 \mathrm{~m}$ after 17 days. Vectors are drawn every third grid point. Solid black lines indicate the position of the ice shelf front and the inner-polynya region (cf. Fig. 3b). The red lines are selected time-average (1-20 days) streamlines drawn to highlight the anticyclonic rim current that forms on the density front between the polynya and the ambient water.

velocities of $0.1-0.2 \mathrm{~m} \mathrm{~s}^{-1}$ and periods of 5-6 days (Fig. 7), although the latter should only be considered indicative because of the shortness of the time series. Enhanced energy at this period is nevertheless close to that observed by Nicholls et al. (2003) in a mooring at the western Ronne Ice Front.

The propagation of HSSW into the cavity is further investigated using a nondiffusive tracer, released at $t=0$ with an initial value of 1 in the open ocean and 0 inside the cavity. After 15 days, the tracer field within the cavity is dominated by the eddy (denoted E1) entering at the western end of the polynya (Fig. 8). This eddy then flows in a southeastward direction with cyclonic motion to the west and anticyclonic motion on the east (not shown). During the 60 days that the model was run, three other large eddies (E2-E4) are seen to propagate into the sub-ice shelf cavity, eventually merging to form a larger inflow branch of HSSW. The location of the inflow is shifted as the salinity front moves westward (Fig. 4), highlighting how eddies generated by frontal instability are driving the inflow of HSSW. The resulting crossshelf salinity distribution (Fig. 9) shows that the inflow occupies almost the entire water column, only constrained by the layer of meltwater found just below the ice shelf. Individual eddies within the cavity are identifiable as domed isohalines, although less visible because of the spatial averaging.

For CTRL, $0.52 \pm 0.03 \mathrm{~Sv}$ of HSSW crosses the ice front and enters the cavity (i.e., $V_{\text {in }}$; Table 1 ). Of the intruding HSSW, $\sim 60 \%$ enters the deep cavity on the time scale considered. Some of this water recirculates, leading to a net transport (i.e., $V_{\text {cav }}$ ) of $0.19 \pm 0.01 \mathrm{~Sv}$ into the deep cavity for CTRL. The time series of net HSSW transport shows a persistent inflow after day 12 (Fig. 10), as well as episodes of increased transport associated with individual eddies (Fig. 8).

\section{Sensitivity studies}

Having established dense water eddies as a driver for exchange between the open ocean and sub-ice shelf cavity, we now test the sensitivity of the strength and properties of the HSSW inflow to forcing parameters. This includes the influence of a wide/narrow frontal zone within the forcing region (WIDE/NARROW), a bigger polynya (BIG), a weaker salt flux (WEAK), an initially stratified water column (STRAT), tides (TIDES), and no basal melting (NOMELT). The model was also run with coarser horizontal grids $(2 \mathrm{~km}$ : COARSE2; $5 \mathrm{~km}$ : COARSE5) to determine how well the processes
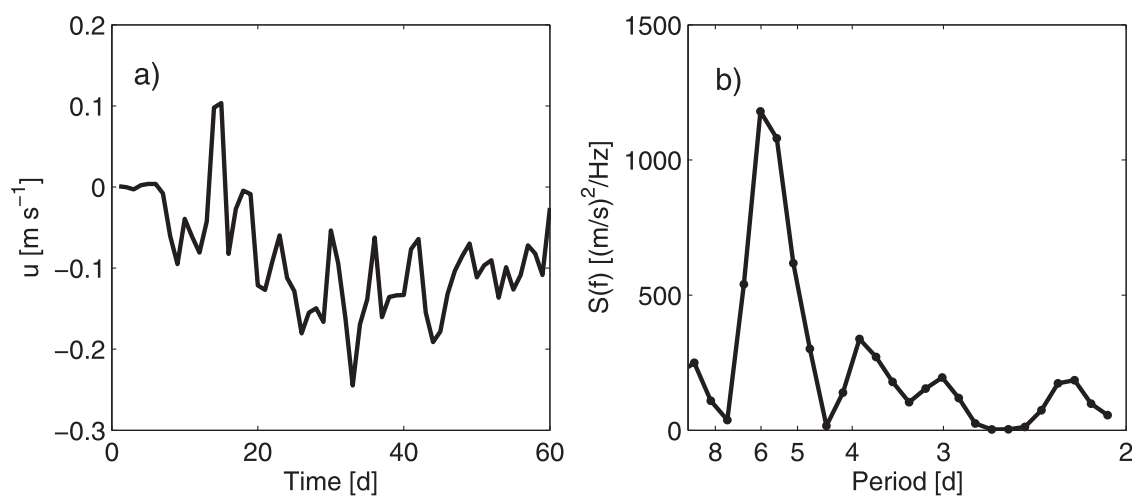

FIG. 7. (a) Time series and (b) power spectrum of the subsurface $(400 \mathrm{~m})$ alongshelf current component at the southwestern corner of the polynya $(x, y=220,180 \mathrm{~km})$. 

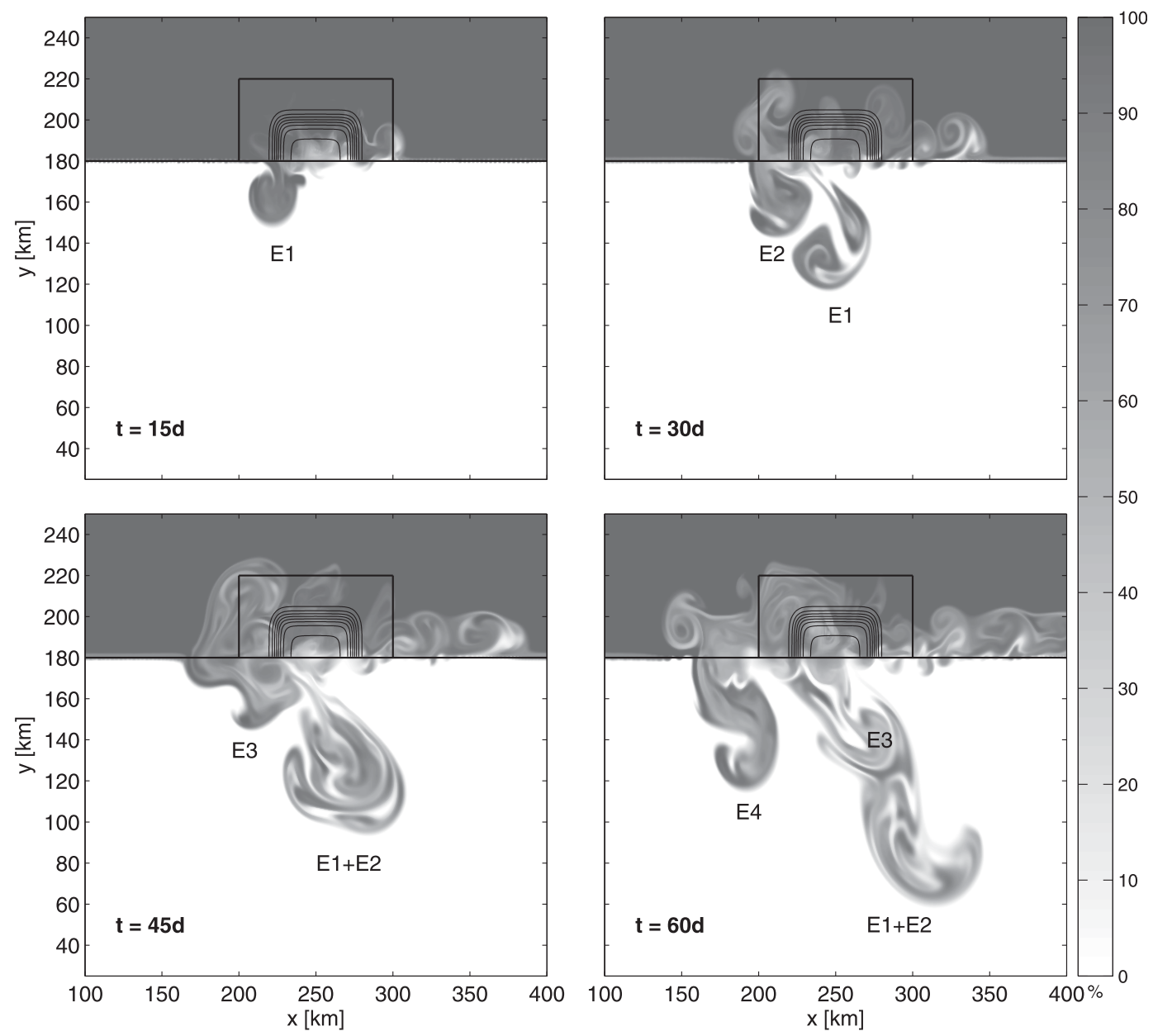

FIG. 8. Tracer concentration (\%) at $400 \mathrm{~m}$ for (top left) 15, (top right) 30, (bottom left) 45, and (bottom right) 60 days. The tracer field is initialized with the ice shelf cavity having a concentration of $0 \%$. The polynya and forcing function (Fig. 3b) are indicated by the black lines. E1-E4 denote the four main eddy-driven inflows and their propagation underneath the ice shelf.

described here should be expected to be represented when applying (still relatively fine resolution) regional or global models to Antarctic shelf seas. Finally, a model run including nonhydrostatic dynamics (NONHYD) is presented. A summary of key results is provided in Table 1.

Other parameters than the ones discussed here could also influence the exchange between the open ocean and sub-ice shelf cavity. For instance, varying ice shelf geometry, involving basal slope and topography, and the thickness of the ice shelf at the ice front (i.e., the step in water column thickness), has the potential to influence the circulation under the ice shelf (see, e.g., Little et al. 2009). As this study is concerned with how eddies drive flow into the cavity and the integrated effect on sub-ice shelf circulation, and not on the sub-ice shelf circulation itself, the sensitivity of the inflow to variations in cavity shape is not assessed.
Variations in bottom topography, for example, a canyon, represent another potential mechanism for driving a flow into the cavity, as this provides a reduced step in water column thickness and therefore a reduced dynamic barrier for barotropic interaction between the cavity and the open ocean (Grosfeld et al. 1997). However, based on observations showing that the flow into the cavity is seasonal even though HSSW is always present at the ice front, Nicholls et al. (2009) argued that this mechanism does not control the cross-ice front exchange. Wilchinsky and Feltham (2008) furthermore showed that the presence of a basal canyon, oriented perpendicular to the coast (ice front in our case), did not notably influence the eddy field and flow generated by buoyancy loss in a coastal polynya. Note, however, that a bathymetric trough can be important for the circulation on Antarctic continental shelves, especially in the 

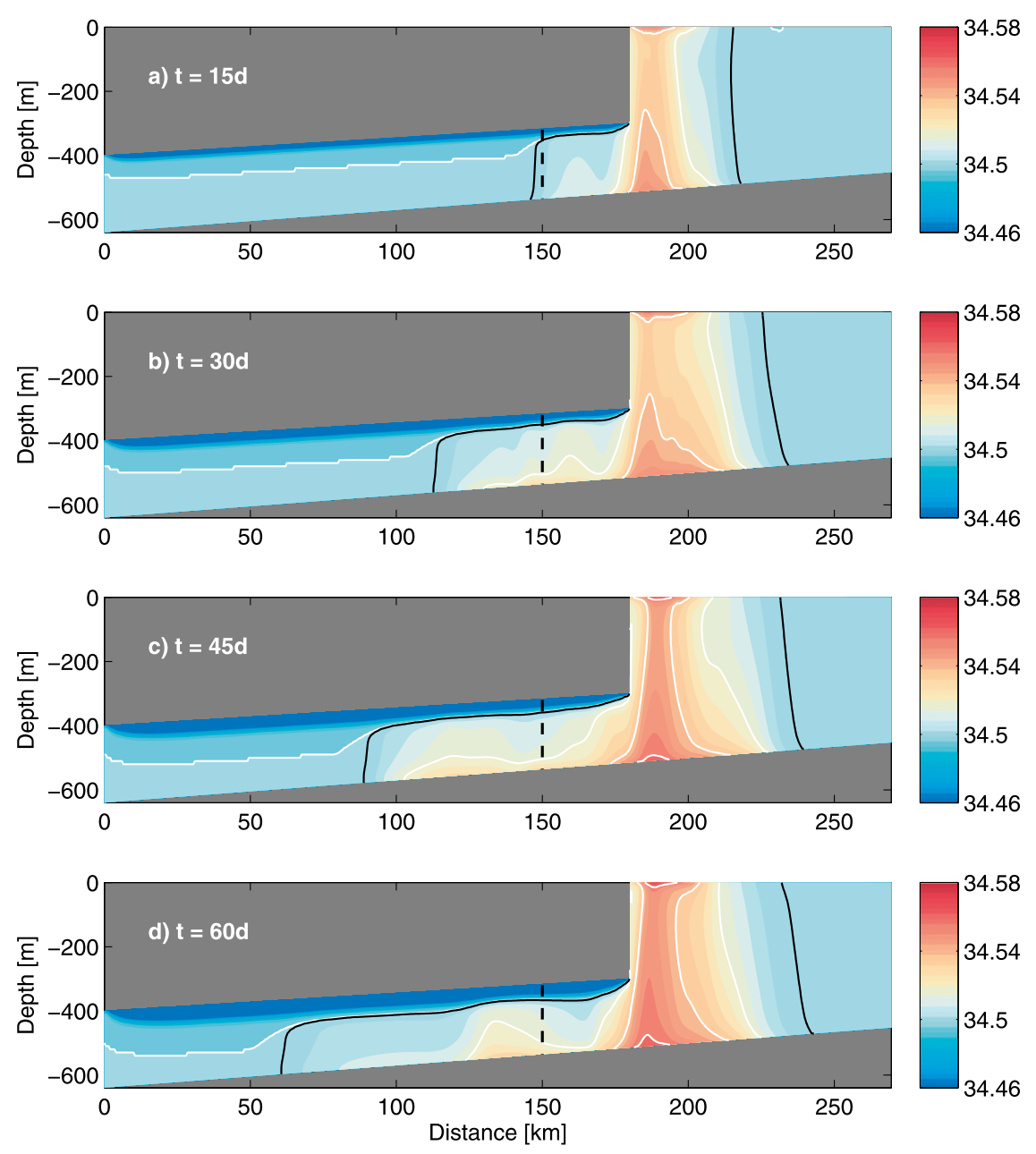

FIG. 9. Temporal evolution of cross-shelf salinity for (a) 15, (b) 30, (c) 45, and (d) 60 days. Isohalines (white contour lines) are drawn every 0.02 starting at 34.5 . The black contour line indicates the extent of HSSW $(S>34.5)$. Sections are averages over the polynya region $(x=$ $200-300 \mathrm{~km})$. The vertical dashed line shows the location where transports are calculated.

onshelf transport of warm water masses (St. Laurent et al. 2013). The presence of a bottom slope can also influence the eddy development and eddy transport away from the polynya (Gawarkiewicz and Chapman 1995; Wilchinsky and Feltham 2008). In the cases considered herein, the ocean bottom slopes down toward the cavity with a slope of $7 \times 10^{-4}$, which represents a gentle slope compared with the cases considered by Gawarkiewicz and Chapman (1995; 0.001-0.005). A gentle southward slope is characteristic for the large Antarctic ice shelves, and sensitivity studies were therefore not performed.

\section{a. Polynya forcing}

As previously outlined, in the case of a polynya with constant buoyancy forcing a balance is eventually reached between the surface buoyancy flux and the lateral buoyancy transport by baroclinic eddies. The density beneath the polynya thus reaches an approximately constant value determined by the terms in this balance. Using the fact that the rim current is in thermal-wind balance $[U=$ $\left(g H / \rho_{0} f\right)\left(\rho L_{f}\right)$, where $U$ is the geostrophic velocity along the rim current and $H$ is the water depth] to approximate the lateral buoyancy flux, Chapman (1999) found that for shallow convection (i.e., the mixed layer depth reaches the seabed) and in the case of no ambient stratification the density anomaly when the surface buoyancy flux and export by eddies is in equilibrium is given by

$$
\rho_{e}=\left(\frac{1}{c_{e}}\right)^{1 / 2} \frac{\rho_{0}}{g H}\left(f L_{f} B_{p} \frac{A}{P}\right)^{1 / 2},
$$

where $B_{p}=Q_{s} \beta g$ is the surface buoyancy flux, $P=2 L_{y}+L_{x}$ is the perimeter of the forcing region with area $A$, and the dimensionless constant $c_{e}$ is a measure of the 


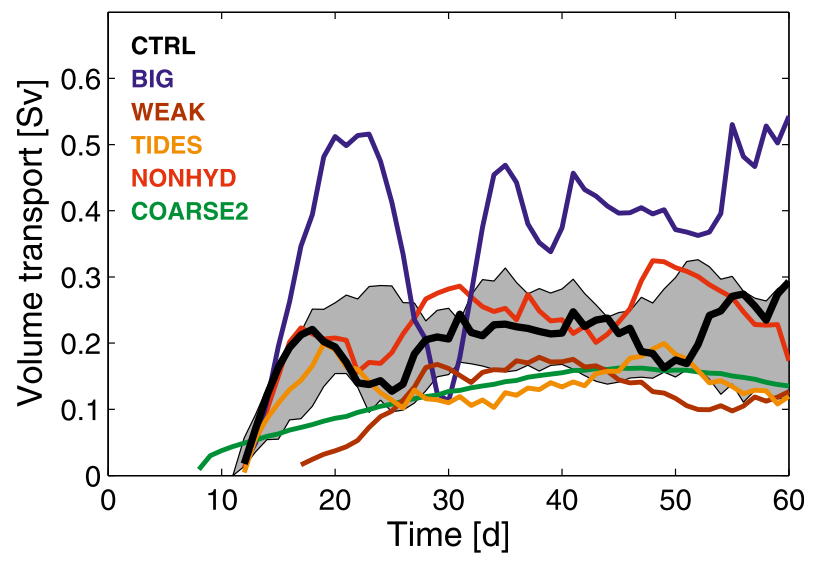

FIG. 10. Time series of net volume transport of polynya water (HSSW, $S>34.5$ ) through a section within the ice shelf cavity ( $y=$ $\left.150 \mathrm{~km}, V_{\text {cav }}\right)$. The gray shading shows the ensemble spread from the 10 perturbation runs.

efficiency with which the eddies transport buoyancy. Similarly, considering the time to reach equilibrium, an expression was derived for the volume rate of dense water formation:

$$
F=c_{e}^{1 / 2} H\left(\frac{B_{p}}{f L_{f}} A P\right)^{1 / 2}
$$

Hence, both the magnitude and shape of the forcing function [Eq. (1)] should influence HSSW formation and transport.

We first consider the influence of forcing decay regions that extend $20 \mathrm{~km}(2 \times$ CTRL: WIDE; Fig. 11$)$ and $5 \mathrm{~km}(0.5 \times$ CTRL: NARROW $)$. As a result of the limited model domain, we have not tested the ocean response to convection also occurring outside the polynya, that is, a forcing decay region that extends over the length of the continental shelf, found by Nicholls et al. (2009) to be necessary to make up the required HSSW production rate. Varying the width of the baroclinic zone leads to small differences in HSSW transport and bottom salinity (Table 1). Values for NARROW are all within the estimated uncertainty for CTRL, whereas there is a slightly larger response in WIDE. The reason for the small change in dense water properties, as opposed to that predicted by Eqs. (3) and (2), could be how the different parameters are defined. Chapman (1999) applied a constant buoyancy flux within the polynya area and a linear or exponential decrease within the forcing decay region, but in this study a smoothly varying hyperbolic tangent function [Eq. (1)] is used throughout. Figure 11 shows that changing the width of the frontal zone also changes the area of maximum buoyancy loss, thus changing parameters $A$ and $P$.

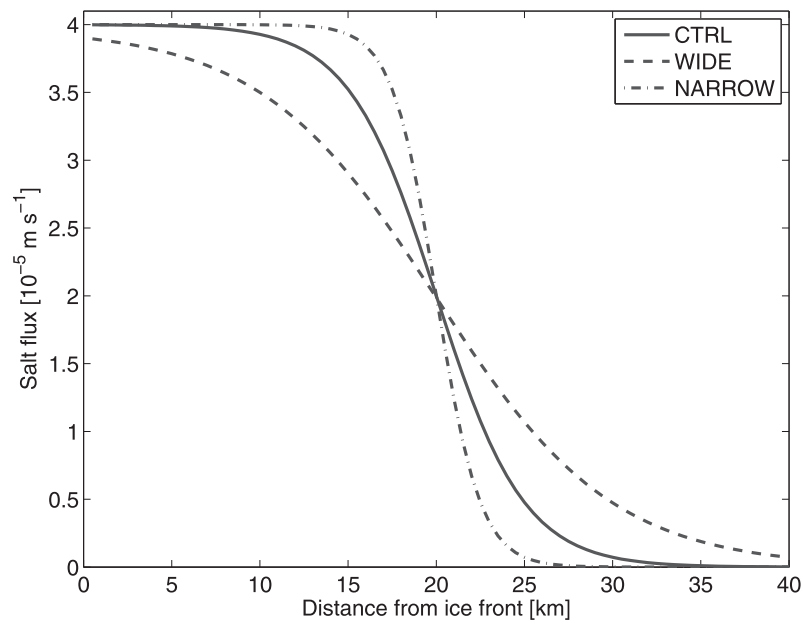

FIG. 11. Cross-shelf profiles of salt flux used to force the model in CTRL, NARROW, and WIDE. The three profiles have a characteristic length scale $\left[L_{f}\right.$ in Eq. (1)] of 10,5 , and $20 \mathrm{~km}$, respectively.

Consistent with Eq. (3), doubling the length and width of the polynya (BIG) leads to a doubling in HSSW transport, whereas a halved surface salt flux (WEAK) reduces the inflow by $\sim 30 \%$ (Table 1 and Fig. 10). Bottom salinities are also significantly influenced in these cases. Flow into the sub-ice shelf cavity is thus more sensitive to the strength of buoyancy forcing and polynya size, that is, the integrated sea ice production, than variations in the spatial distribution of the dense water source.

\section{b. Stratification}

The influence of stratification is tested by initializing the model with a surface salinity of 34.6, increasing linearly to 34.8 at $650 \mathrm{~m}$. This yields a constant buoyancy frequency of $N=0.0016 \mathrm{~s}^{-1}$, which is a typical value for early winter stratification in the Weddell Sea (Foldvik et al. 1985; Årthun et al. 2013). The convection starts to erode the stratification underneath the polynya within 10 days (not shown). The resulting density anomaly within the convective chimney is, however, not sufficient to force an inflow into the deep cavity (STRAT; Table 1), the HSSW mainly being confined to within $30 \mathrm{~km}$ of the ice front (Fig. 12). Note that the HSSW transport is calculated differently for this case, using a tracer concentration larger than 50\% rather than $S>$ 34.5 to identify HSSW. The cutoff was chosen by comparing results using both definitions for the other cases. Stratification also suppresses mixing, evident by higher tracer concentrations in the inflowing water. As the model is only run for 60 days (limited by the size of the domain), this case should be considered to represent an early preconditioning stage leading to the unstratified 

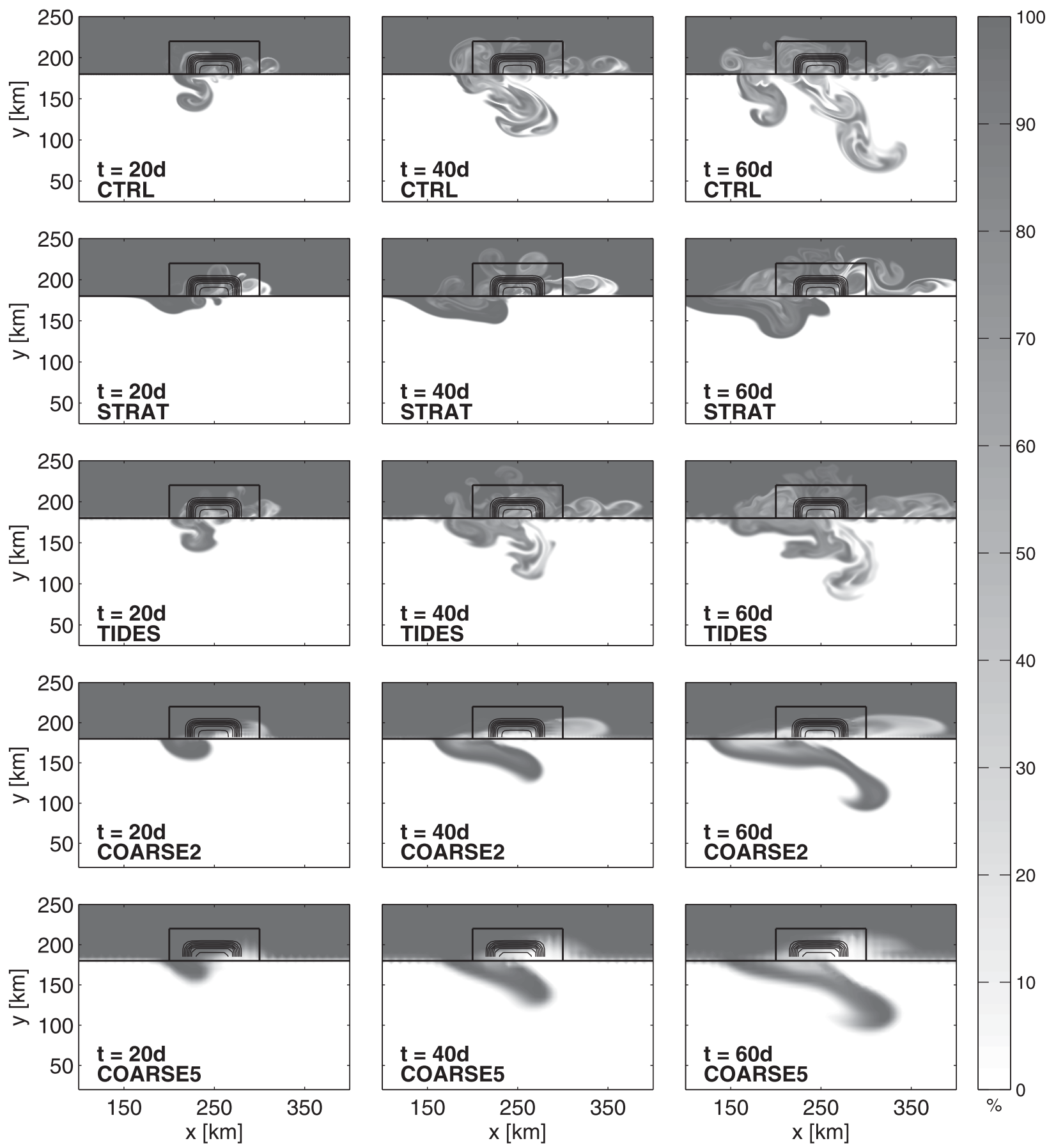

FIG. 12. Tracer concentration (\%) at $400 \mathrm{~m}$ for cases (top) CTRL, (upper middle) STRAT, (middle) TIDES, (lower middle) COARSE2, and (bottom) COARSE5. The tracer field is initialized with the ice shelf cavity having a concentration of $0 \%$. The polynya and forcing function are indicated by the black lines.

conditions discussed in CTRL and the other sensitivity runs.

\section{c. Tides}

Tidal activity has been shown to play an important role in the circulation under ice shelves by modifying the mean flow through a combination of processes, including higher mixing, residual flows, and by influencing basal melting and the associated meltwater-driven thermohaline circulation beneath the ice shelf (Robertson et al. 1998; Makinson and Nicholls 1999; Makinson et al. 2011). The response of sub-ice shelf circulation to tidal forcing, 
and the relative importance of processes determining this response, is sensitive to the specific tidal regime, that is, the relative strength of background flow and tidal flow, and the location of the ice shelf relative to the critical latitude (Makinson et al. 2006). Our idealized model is not capable of simulating the full impact of tides. For instance, the model is not capable of realistically representing tidal residual currents as these currents result from spatial variations in the tidal current as a result of interaction with topography. However, the isolated impact of an oscillating background current on the eddydriven HSSW transport can be established.

A semidiurnal $M_{2}$ tidal current is added on the northern and southern boundary by specifying oscillating external velocity components $V_{T}=V_{0} \cos (2 \pi t / T)$ normal to the boundaries with period $T=12.42 \mathrm{~h}$ and amplitudes $V_{0}=7.5 \mathrm{~cm} \mathrm{~s}^{-1}$ and $V_{0}=12 \mathrm{~cm} \mathrm{~s}^{-1}$ on the northern and southern boundary, respectively. It is assumed that the ice shelf cavity extends farther south. Different tidal velocities are prescribed in order to maintain a constant volume transport through the two open boundaries, which have different water column thicknesses (Fig. 3a). The magnitude of the tidal currents are typical for the barotropic $M_{2}$ tidal current on the Weddell Sea continental shelf, but lower than that found close to the Ronne Ice Front (Robertson et al. 1998; Makinson and Nicholls 1999).

The inclusion of a tidal current leads to a reduction in HSSW transport into the deep cavity (TIDES; Table 1 and Fig. 10). This contrasts with previous modeling studies such as Makinson et al. (2011), who found that including tides in a regional model setup of the Weddell Sea increased the inflow of HSSW into the Ronne cavity by $63 \%$, but is consistent with Robertson et al. (1998) who, considering only the effect of tidally enhanced bottom friction, found that the inclusion of tides in a simulation of the Weddell Sea reduced the mean flow by $30 \%$. The weaker and more diffuse penetration of HSSW in TIDES (Fig. 12) is consistent with enhanced mixing by tidal stirring.

\section{d. Basal melt}

The density front where the eddies form is also influenced by freshwater input from the prescribed basal melt. Removal of basal melt does not change the results notably (NOMELT; Table 1), in agreement with the low sensitivity to changes in the forcing decay region.

\section{e. Grid size}

Modern regional models used for studies of Antarctic shelf seas commonly have a horizontal resolution on the order of a few kilometers (e.g., Dinniman et al. 2011; Makinson et al. 2011; Galton-Fenzi et al. 2012;
Timmermann et al. 2012), while historical and global models are coarser still (e.g., Grosfeld et al. 1997; Jenkins et al. 2004; Losch 2008). Although their model produced a wintertime inflow underneath Ronne Ice Shelf as a result of HSSW formation, Jenkins et al. (2004, p. 10) noted that the process of convection and production of geostrophic eddies could only be "crudely parameterized through the diffusive flattening of isopycnal layer interfaces." To test the influence of different resolution, we run the model with grid sizes of 2 (COARSE2) and $5 \mathrm{~km}$ (COARSE5). The horizontal diffusivity and viscosity were scaled linearly with grid size to ensure a consistent mixing velocity, according to mixing-length theory. Higher values of diffusivity and viscosity are also necessary for numerical stability.

Running the model on a coarser grid has a significant influence on both the strength and salinity of the dense water inflow (Table 1 and Fig. 10). Lower resolution reduces the horizontal density gradients between the polynya and the ambient water. The eddy velocities scale like the velocity along the rim current, which is in thermal-wind balance (Haine and Marshall 1998), so the weaker gradients lead to a lower inflow. Poorer resolution of the velocity field also permits less shear. The weaker density and velocity gradients suppress baroclinic instability and the resulting eddies. The tracer field for COARSE2 (Fig. 12) shows that the inflow takes place at the same location as CTRL, but as one smooth inflow branch, rather than in the form of eddies. Suppression of baroclinic instability is also evident if the domainintegrated eddy kinetic energy is used as a measure of eddy activity. In CTRL, the EKE represents $68 \%$ of the total kinetic energy, decreasing to $40 \%$ and $22 \%$ for COARSE2 and COARSE5, respectively.

The comparison of results from CTRL and COARSE2/ COARSE5 suggests that the results correspond to an eddy-resolving model $\left(1 / 40^{\circ}\right.$ at $\left.80^{\circ} \mathrm{S}\right)$ compared to eddypermitting models $\left(1 / 10^{\circ}\right.$ and $\left.1 / 4^{\circ}\right)$. It is notable that the eddy field is poorly resolved at $1 / 10^{\circ}$, which is usually considered eddy-resolving resolution. Our results are in agreement with St. Laurent et al. (2013), who found that the onshore heat transport through a coastal trough became substantially reduced when the model grid spacing was not eddy resolving $(>1 \mathrm{~km})$. We did not test a further refinement of the model grid because of the computational cost. A more dedicated quantification of the resolution required to accurately simulate mesoscale eddy fluxes in Antarctic shelf seas is warranted. The inability to resolve shelf processes-including but not limited to processes discussed herein-in present day climate models has been found to cause important deficiencies in modeled bottom water properties in the Southern Ocean (Heuzé et al. 2013). 


\section{f. Nonhydrostatic}

Including nonhydrostatic dynamics increases the inflow of HSSW into the sub-ice shelf cavity by $21 \%$ (NONHYD; Table 1 and Fig. 10). This is, however, a result of the HSSW occupying a greater range of depths in the cavity and not a change in horizontal velocities. The vertical velocity in the convective plumes is reduced compared with CTRL; the downwelling maxima being approximately $2 \mathrm{~cm} \mathrm{~s}^{-1}$. The pattern of propagation of HSSW within the cavity is still qualitatively similar for the hydrostatic and nonhydrostatic case (not shown) and is in agreement with Mahadevan (2006) who found no characteristic differences in submesoscale $[O(1 \mathrm{~km})]$ structures between a nonhydrostatic and a hydrostatic model at a resolution of $1 \mathrm{~km}$ and $500 \mathrm{~m}$. For the grid resolution used here there is thus a limited influence of nonhydrostatic dynamics, and a further refinement of the model grid is probably necessary for nonhydrostatic effects to become important (Marshall et al. 1997b).

\section{Discussion}

We have shown that for an idealized ice shelf-open ocean model setup, eddies generated by buoyancy loss within a polynya represent an important mechanism for exchange between the open ocean and a sub-ice shelf cavity. The setup was based on the geometry and forcing of the Ronne Ice Shelf and polynya. Ice-front polynyas are also found near other large Antarctic ice shelves (Tamura et al. 2008), such as Ross Ice Shelf and Amery Ice Shelf, so our results should be relevant there.

Although the applied model is not expected to reproduce the observed flow of HSSW into the Ronne Ice Shelf cavity, it is still interesting to discuss features of the simulated HSSW inflow with respect to existing observations. Based on data from two ice-front moorings, Nicholls et al. (2003) estimated the inflow of HSSW to be $0.9 \pm 0.3 \mathrm{~Sv}$. The main inflow was observed at the western end of the ice front, and was considered to occur as a result of the generally westward-flowing current meeting the Antarctic Peninsula. The position of the inflow is, however, also consistent with a polynya rim current intersecting the ice front at its southwestern corner, as seen in Fig. 6 and Fig. 8. A model run with the polynya next to a lateral wall, mimicking the Antarctic Peninsula, was not done. Assuming that a density gradient would still exist between the central polynya and the coast of the peninsula (Fig. 2 shows the polynya tailing off toward the wall), the conditions for HSSW transport by baroclinic eddies are fulfilled. This is supported by observations of eddies at the western Ronne Ice Front (Nicholls et al. 2003; Makinson and Schröder 2004) with similar length and time scale as that seen in the simulations. The presence of a lateral wall might cause the inflow to become narrower and faster as the dense water cannot spread westward (as seen in Fig. 4) but would not change the total inflow.

In a recent model study Haid and Timmermann (2013) found that the average wintertime (May-September) ice production in the Ronne polynya between 1990 and 2009 was $43.8 \mathrm{~km}^{3}\left(0.13 \mathrm{~m} \mathrm{day}^{-1}\right)$, with an interannual standard deviation of $26.6 \mathrm{~km}^{3}$, that is, $61 \%$ of the mean value. The modeled ice production in Haid and Timmermann (2013) agrees well with previous estimates based on atmospheric reanalysis data and satellitederived sea ice products (Renfrew et al. 2002; Tamura et al. 2008). The size of the polynya, defined as the area where sea ice concentration is less than $70 \%$, was found to vary interannually from $<1000$ to $>5000 \mathrm{~km}^{2}$, with an average of about $2000 \mathrm{~km}^{2}$. The region of main buoyancy loss in CTRL $\left(Q_{s}>5 \times 10^{-7} \mathrm{~m} \mathrm{~s}^{-1}\right.$ in Fig. 3b) and BIG corresponds to an area of about 1200 and $4800 \mathrm{~km}^{2}$, respectively. Assuming constant salt fluxes for 5 months the equivalent integrated wintertime ice production for these two cases is 17 and $66 \mathrm{~km}^{3}$, thus capturing the range of variability. The average HSSW transport into the deep cavity for these cases is 0.20 and $0.37 \mathrm{~Sv}$, with peak values of $\sim 0.3$ and $\sim 0.5 \mathrm{~Sv}$ at the end of the simulation (Fig. 10). Considering that the model is not capable of simulating tidal residual currents, a process capable of flushing the cavity at a rate of $0.35 \mathrm{~Sv}$ (Makinson and Nicholls 1999), and has no background Weddell Sea flow, the simulated HSSW inflow is consistent with that observed.

The sensitivity of HSSW flow into the sub-ice shelf cavity to the strength of the surface buoyancy flux and size of the polynya suggests that any interannual variability in sea ice production within the polynya should be reflected within the cavity. Pronounced interannual variability underneath Filchner-Ronne Ice Shelf as a result of anomalous ocean forcing at the ice front has been observed by Nicholls and Østerhus (2004). Using a combination of observations and reanalysis, Drucker et al. (2011) found a significant 1992-2008 trend in the Ronne polynya ice production, which is due to a decrease in the wind-driven northward export of ice in this region (Holland and Kwok 2012). As a large fraction of the dense overflow from the continental shelf into the deep Weddell Sea originates from sea ice formation in the Ronne polynya and the following transformation of HSSW into ISW underneath the ice shelf (Nicholls and Makinson 1998; Foldvik et al. 2004), variations in HSSW/ ISW production and properties could translate into variability in bottom water properties in the Weddell Sea. Given the decadal decrease in polynya sea ice production, it may be no coincidence that AABW is contracting in this region (Purkey and Johnson 2012). 
The focus of this paper has been on transient simulations over a relatively short time scale, and we have restricted our attention to the flow of HSSW into the ice shelf cavity during winter when large heat loss and associated sea ice production leads to active convection within the Ronne polynya. This allows us to isolate one potential mechanism for the HSSW inflow and assess its sensitivity to different parameters. We have thus not considered the southward propagation and modification of HSSW through interaction with the ice shelf base, or the interaction with other water masses at the ice front, which would require a larger, more realistic domain and the inclusion of ice shelf thermodynamics. A key result from our simulations is that sub- $1 \mathrm{~km}$ grid resolution must be used in future numerical investigations of subice shelf flow, as otherwise the eddy-driven inflow is substantially reduced. The limited time period considered here (restricted by the size of the domain) also means that the numerical integration never reaches a statistically steady state. Our simulations only reflect the sharp onset of HSSW production during winter, and do not consider the development of the eddy field during the transition to summer/autumn conditions when the water column north of the ice front is restratified and the inflow gradually shuts down (Jenkins et al. 2004). The seasonal forcing of the surface ocean, however, consistently returns conditions on the southern Weddell Sea continental shelf to that used as initial conditions in our model runs (i.e., well-mixed water column, ice-covered ocean with coastal polynyas), and we would therefore expect our results also to apply if the model was run for several years and a steady state could be reached, assuming the background flow remained weak.

\section{Summary and conclusions}

Strong interaction between atmosphere, ocean, and ice in Antarctic shelf seas make them important dense water formation sites. In the Weddell Sea, ice-front polynyas are responsible for producing cold, dense highsalinity shelf water (HSSW). Some of the HSSW flows into the Filchner-Ronne cavity, and its interaction with the ice shelf base is an important part of bottom water formation in the Weddell Sea (Foldvik et al. 2004). Here, we have used a high-resolution numerical model with an idealized setup of the open ocean-ice shelf system to address the importance of eddies in controlling flow of dense water into the ice shelf cavity.

An ice-front polynya is represented by a steady, spatially varying salt flux into the ocean, which is comparable to that observed in the Ronne polynya. Buoyancy loss within the polynya leads to the formation of a front between the dense polynya water and lighter ambient water, which supports a geostrophic rim current. Eddies produced on the front by baroclinic instability are able to enter the cavity at the southwestern corner of the polynya, where the rim current intersects the ice shelf front. The strength and salinity of the inflow are sensitive to the size of the polynya and the surface buoyancy flux, suggesting that the large interannual variability in sea ice production observed in the Ronne polynya is manifested in water masses found within the sub-ice shelf cavity.

Reducing the horizontal resolution of the model from $500 \mathrm{~m}$ to $2 \mathrm{~km}$ or $5 \mathrm{~km}$, that is, from eddy-resolving to eddy-permitting, substantially diminishes the inflow to the cavity. This sensitivity of the HSSW inflow to model resolution represents a considerable challenge for present day climate models to accurately represent water masses produced in Antarctic shelf seas. The intimate connection between ice production and HSSW inflow to the cavity may represent a link between the observed reduction in sea ice production in the Ronne polynya during the last decades (Drucker et al. 2011) and the concurrent contraction of AABW in the Weddell Sea (Purkey and Johnson 2012).

Acknowledgments. This study was supported by the U.K. Natural Environment Research Council, Grant NE/I025867/1. We thank two anonymous reviewers for valuable comments and suggestions.

\section{REFERENCES}

Årthun, M., K. W. Nicholls, and L. Boehme, 2013: Wintertime water mass modification near an Antarctic Ice Front. J. Phys. Oceanogr., 43, 359-365.

Chapman, D. C., 1998: Setting the scales of the ocean response to isolated convection. J. Phys. Oceanogr., 28, 606-620.

_- 1999: Dense water formation beneath a time-dependent coastal polynya. J. Phys. Oceanogr., 29, 807-820.

_ , and G. Gawarkiewicz, 1997: Shallow convection and buoyancy equilibration in an idealized coastal polynya. J. Phys. Oceanogr., 27, 555-566.

Determann, J., and R. Gerdes, 1994: Melting and freezing beneath ice shelves-Implications from a three-dimensional ocean circulation model. Ann. Glaciol., 20, 413-419, doi:10.3189/ 172756494794587591.

Dietrich, D., and C. A. Lin, 2002: Effects of hydrostatic approximation and resolution on the simulation of convective adjustment. Tellus, 54A, 34-43, doi:10.1034/j.1600-0870.2002.00162.x.

Dinniman, M. S., J. M. Klinck, and W. O. Smith Jr., 2011: A model study of Circumpolar Deep Water on the West Antarctic Peninsula and Ross Sea continental shelves. Deep-Sea Res. II, 58 (13-16), 1508-1523, doi:10.1016/j.dsr2.2010.11.013.

Drucker, R., S. Martin, and R. Kwok, 2011: Sea ice production and export from coastal polynyas in the Weddell and Ross Seas. Geophys. Res. Lett., 38, L17502, doi:10.1029/2011GL048668.

Fiedler, E. K., T. A. Lachlan-Cope, I. A. Renfrew, and J. C. King, 2010: Convective heat transfer over thin ice-covered 
coastal polynyas. J. Geophys. Res., 115, C10051, doi:10.1029/ 2009JC005797.

Foldvik, A., T. Gammelsrød, and T. Tørresen, 1985: Circulation and water masses on the southern Weddell Sea shelf. Oceanology of the Antarctic Continental Shelf, Antarctic Research Series, Vol. 43, Amer. Geophys. Union, 5-20.

,-- , E. Nygaard, and S. Østerhus, 2001: Current measurements near Ronne ice shelf: Implications for circulation and melting. J. Geophys. Res., 106 (C3), 4463-4477.

_ and Coauthors, 2004: Ice shelf water overflow and bottom water formation in the southern Weddell Sea. J. Geophys. Res., 109, C02015, doi:10.1029/2003JC002008.

Galton-Fenzi, B. K., J. R. Hunter, R. Coleman, S. J. Marsland, and R. C. Warner, 2012: Modeling the basal melting and marine ice accretion of the Amery Ice Shelf. J. Geophys. Res., 117, C09031, doi:10.1029/2012JC008214.

Gawarkiewicz, G., and D. C. Chapman, 1995: A numerical study of dense water formation and transport on a shallow, sloping continental shelf. J. Geophys. Res., 100 (C3), 4489-4507.

Grosfeld, K., R. Gerdes, and J. Determann, 1997: Thermohaline circulation and interaction between ice shelf cavities and the adjacent open ocean. J. Geophys. Res., 102 (C7), 1559515610.

Haid, V., and R. Timmermann, 2013: Simulated heat flux and sea ice production at coastal polynyas in the southwestern Weddell Sea. J. Geophys. Res., 118, 2640-2652.

Haine, T. W. N., and J. Marshall, 1998: Gravitational, symmetric, and baroclinic instability of the ocean mixed layer. J. Phys. Oceanogr., 28, 634-658.

— , and P. D. Williams, 2002: The role of nonhydrostatic dynamics in controlling development of a surface ocean front. Ocean Modell., 4, 121-135, doi:10.1016/S1463-5003(01)00014-2.

Heuzé, C., K. J. Heywood, D. P. Stevens, and J. K. Ridley, 2013: Southern Ocean bottom water characteristics in CMIP5 models. Geophys. Res. Lett., 40, 1409-1414, doi:10.1002/ grl.50287.

Holland, D. M., and A. Jenkins, 2001: Adaptation of an isopycnic coordinate ocean model for the study of circulation beneath ice shelves. Mon. Wea. Rev., 129, 1905-1927.

Holland, P. R., and R. Kwok, 2012: Wind-driven trends in Antarctic sea ice drift. Nat. Geosci., 5, 872-875, doi:10.1038/NGEO1627.

Hollands, T., V. Haid, W. Dierking, R. Timmermann, and L. Ebner, 2013: Sea ice motion and open water area at the Ronne polynya, Antarctica: Synthetic aperture radar observations versus model results. J. Geophys. Res., 118, 1-15, doi:10.1002/ jgrc. 20158 .

Jacobs, S. S., 2004: Bottom water production and its links with the thermohaline circulation. Antarct. Sci., 16, 427-437, doi:10.1017/ S095410200400224X.

Jenkins, A., and C. S. M. Doake, 1991: Ice-ocean interaction on the Ronne Ice Shelf, Antarctica. J. Geophys. Res., 96 (C1), 791813.

— D. M. Holland, K. W. Nicholls, M. Schröder, and S. Østerhus, 2004: Seasonal ventilation of the cavity beneath FilchnerRonne Ice Shelf simulated with an isopycnic coordinate ocean model. J. Geophys. Res., 109, C01024, doi:10.1029/ 2001JC001086.

Joughin, I., and L. Padman, 2003: Melting and freezing beneath Filchner-Ronne Ice Shelf, Antarctica. Geophys. Res. Lett., 30, 1477, doi:10.1029/2003GL016941.

Little, C. M., A. Gnanadesikan, and M. Oppenheimer, 2009: How ice shelf morphology controls basal melting. J. Geophys. Res., 114, C12007, doi:10.1029/2008JC005197.
Losch, M., 2008: Modeling ice shelf cavities in a $z$-coordinate ocean general circulation model. J. Geophys. Res., 113, C08043, doi:10.1029/2007JC004368.

Mahadevan, A., 2006: Modeling vertical motion at ocean fronts: Are nonhydrostatic effects relevant at submesoscales? Ocean Modell., 14 (3-4), 222-240, doi:10.1016/j.ocemod.2006.05.005.

Makinson, K., and K. Nicholls, 1999: Modeling tidal currents beneath Filchner-Ronne Ice Shelf and on the adjacent continental shelf: Their effect on mixing and transport. J. Geophys. Res., 104 (C6), 13449-13465.

_ inflow along Ronne Ice Front. Forum Ressearch Ice Shelf Processes, Vol. 15, Bjerknes Center for Climatic Research, $11-16$.

,-- , and S. Østerhus, 2006: Effect of critical latitude and seasonal stratification on tidal current profiles along Ronne Ice Front, Antarctica. J. Geophys. Res., 111, C03022, doi:10.1029/ 2005JC003062.

— , P. R. Holland, A. Jenkins, K. W. Nicholls, and D. M. Holland, 2011: Influence of tides on melting and freezing beneath Filchner-Ronne Ice Shelf, Antarctica. Geophys. Res. Lett., 38, L06601, doi:10.1029/2010GL046462.

Marshall, J., A. Adcroft, C. Hill, L. Perelman, and C. Heisey, 1997a: A finite-volume, incompressible Navier-Stokes model for studies of the ocean on parallel computers. J. Geophys. Res., 102 (C3), 5753-5766.

— C. Hill, L. Perelman, and A. Adcroft, 1997b: Hydrostatic, quasi-hydrostatic, and nonhydrostatic ocean modeling. J. Geophys. Res., 102 (C3), 5733-5752.

Mathiot, P., N. C. Jourdain, B. Barnier, H. Gallée, J. M. Molines, J. Le Sommer, and T. Penduff, 2012: Sensitivity of coastal polynyas and high-salinity shelf water production in the Ross Sea, Antarctica, to the atmospheric forcing. Ocean Dyn., 62, 701-723, doi:10.1007/s10236-012-0531-y.

McDougall, T. J., D. R. Jackett, D. G. Wright, and R. Feistel, 2003 : Accurate and computationally efficient algorithms for potential temperature and density of seawater. J. Atmos. Oceanic Technol., 20, 730-741.

Muench, R. D., L. Padman, S. L. Howard, and E. Fahrbach, 2002: Upper-ocean diapycnal mixing in the northwestern Weddell Sea. Deep-Sea Res. II, 49, 4843-4861, doi:10.1016/ S0967-0645(02)00162-5.

Nicholls, K. W., 1996: Temperature variability beneath Ronne Ice Shelf, Antarctica, from thermistor cables. J. Geophys. Res., 101 (C1), 1199-1210.

—, and K. Makinson, 1998: Ocean circulation beneath the western Ronne Ice Shelf, as derived from in situ measurements of water currents and properties. Ocean, Ice, and Atmosphere: Interactions at the Antarctic Continental Margins, S. S. Jacobs and R. F. Weiss, Eds., Antarctic Research Series, Vol. 75, Amer. Geophys. Union, 301-318.

_ , and S. Østerhus, 2004: Interannual variability and ventilation time scales in the ocean cavity beneath Filchner-Ronne Ice Shelf, Antarctica. J. Geophys. Res., 109, C04014, doi:10.1029/ 2003JC002149.

— , L. Padman, M. Schröder, R. A. Woodgate, A. Jenkins, and S. Østerhus, 2003: Water mass modification over the continental shelf north of Ronne Ice Shelf, Antarctica. J. Geophys. Res., 108, 3260, doi:10.1029/2002JC001713.

, S. Østerhus, K. Makinson, T. Gammelsrød, and E. Fahrbach, 2009: Ice-ocean processes over the continental shelf of the southern Weddell Sea, Antarctica: A review. Rev. Geophys., 47, RG3003, doi:10.1029/2007RG000250. 
Pedlosky, J., 1987: Geophysical Fluid Dynamics. Springer-Verlag, New York.

Purkey, S. G., and G. C. Johnson, 2012: Global contraction of Antarctic Bottom Water between the 1980s and 2000s. J. Climate, 25, 5830-5844.

Renfrew, I. A., J. C. King, and T. Markus, 2002: Coastal polynyas in the southern Weddell Sea: Variability of the surface energy budget. J. Geophys. Res., 107 (C6), doi:10.1029/ 2000JC000720.

Robertson, R., L. Padman, and G. D. Egbert, 1998: Tides in the Weddell Sea. Ocean, Ice, and Atmosphere: Interactions at the Antarctic Continental Margins, S. S. Jacobs and R. F. Weiss, Eds., Antarctic Research Series, Vol. 75, Amer. Geophys. Union, 341-369.

Spreen, G., L. Kaleschke, and G. Heygster, 2008: Sea ice remote sensing using AMSR-E 89-GHz channels. J. Geophys. Res., 113, C02S03, doi:10.1029/2005JC003384.

St. Laurent, P., J. M. Klinck, and M. S. Dinniman, 2013: On the role of coastal troughs in the circulation of warm circumpolar deep water on Antarctic shelves. J. Phys. Oceanogr., 43, 51-64.
Tamura, T., K. I. Ohshima, and S. Nihashi, 2008: Mapping of sea ice production for Antarctic coastal polynyas. Geophys. Res. Lett., 35, L07606, doi:10.1029/2007GL032903.

Timmermann, R., Q. Wang, and H. H. Hellmer, 2012: Ice-shelf basal melting in a global finite-element sea-ice/ice-shelf/ ocean model. Ann. Glaciol., 53, 303-314, doi:10.3189/ 2012AoG60A156.

Visbeck, M., J. Marshall, and H. Jones, 1996: Dynamics of isolated convective regions in the ocean. J. Phys. Oceanogr., 26, 17211734.

Weppernig, R., P. Schlosser, S. Khatiwala, and R. G. Fairbanks, 1996: Isotope data from ice station Weddell: Implications for deep water formation in the Weddell Sea. J. Geophys. Res., 101 (C11), 25723-25739.

Wilchinsky, A. V., and D. L. Feltham, 2008: Generation of a buoyancydriven coastal current by an Antarctic polynya. J. Phys. Oceanogr., 38, 1011-1032.

, and - 2009: Numerical simulation of the Filchner overflow. J. Geophys. Res., 114, C12012, doi:10.1029/2008JC005013. 